\title{
Benefits of Antenatal Care Utilization: The Knowledge of Pregnant Women, in Addis Ababa, Ethiopia, 2015
}

\author{
Eyasu Tamru Bekru* \\ Department of Nursing, College of Medicine and Health Sciences, \\ Wolaita Sodo University, Sodo, Ethiopia \\ Fantaneshi Desalegn \\ Addis Ababa City Administration Health Bureau, Addis Ababa, Ethiopia \\ Bezalem Eshetu Yirdaw \\ Affiliation: \\ Department of statistics, college of natural and computational science, \\ Wolaita Sodo University, Sodo, Ethiopia
}

\begin{abstract}
The research is financed by Addis Ababa university
\section{Abstract}

Antenatal Care means care before birth and includes education, counseling, screening and treatment to monitor and to promote the well - being of the mother and fetus. The aim of this study is to assess knowledge of pregnant women regarding the benefits of Antenatal care in Addis Ababa, Ethiopia. Cross-sectional study was conducted among 405 pregnant women from March to April, 2015. Participants were interviewed using structured questionnaire. Descriptive statistics was used to describe the study variables. Multivariate analysis was used to assess the relative effect of determinants. AP $<0.05$ was considered statistically significant in all tests of significance. From total of 405 women interviewed 59.3 percent of them were found to have good knowledge about ANC services. Education level, partner support were found to have good Knowledge towards ANC and previous history of health care for recent pregnancy was determinant of knowledge to war utilization of ANC. Participants Knowledge of ANC and their knowledge on certain aspects of antenatal care were still poor. . As a long term strategy to reaching all segments of the population, women empowerment through education and income generating activities as well as with involvement of husbands during information education and communication would have to be intensified on ANC programs.
\end{abstract}

Keywords: Knowledge, pregnant women, ANC, Addis Ababa.

DOI: $10.7176 / \mathrm{JHMN} / 60-04$

Publication date:March $31^{\text {st }} 2019$

\section{Background}

Antenatal Care (ANC), is a care before birth for pregnant women and includes education, counseling, screening and treatment to monitor and to promote the well - being of the mother and fetus. It is the care that a woman receives during pregnancy to ensure healthy out comes for women and newborn (Adewoye et al., 2013).

It is a key entry point for pregnant women to receive a multiple range of health services such as nutritional support and prevention or treatment of anemia; prevention, detection and treatment of malaria, tuberculosis and sexually transmitted infections. In addition, it is an opportunity to promote the benefits of skilled attendance at birth and to encourage women to seek postpartum care for themselves and their newborn. It is also an ideal time to counsel women about the benefits of child spacing (Kalayou et al., 2014; Yang et al., 2010).

However, Antenatal Care have such attractive benefits and strategies, according to the, every year, at least half a million women and girls die as a result of complications during pregnancy, childbirth or the six weeks following delivery and almost all (99\%) of these deaths occur in developing countries. This shows that the Antenatal care activity is very weak in developing country (Ojo 2004; WHO et.at., 2007).

To alleviate such factors, Antenatal care is the best mechanism to minimize maternal mortality, and give a good information for pregnant women about their birth and how to prevent related problems. The best and most advantage of Antenatal Care is to protect the health of women's and their infants as well as indicating the danger signals that will be occurred and needs to be further treated by advanced health professionals (Effendi et al.,2008; Amosu et al., 2011).

Every minute, at least one woman dies from complications related to pregnancy or child birth that means 529 000 women a year. Based on EDHS 2011 report, in Ethiopia the maternal mortality rate has been estimated to be 676 per 100,000 live births with anti-natal coverage of 43\% (WHO, 1992; Orc M et al.,2011)

To combat the major maternal health problem and tackle unwanted outcomes of pregnancy, antenatal care (ANC) is the only and most important method in detecting and treating pregnancy problems in its earliest period (Regassa 2011). 
In another cross-sectional study conducted in Metekel zone, North West Ethiopia, 65.6\% of women interviewed knew at least half of the knowledge questions on ANC and so labeled as knowledgeable. In the same study, Among the socio-demographic factors; being in urban residence, possessing radio and educational status of secondary school and above were more than 4 times, two times, and three times more likely to be knowledgeable about ANC (Gurmesa 2009).

It could be in realization that knowledge of pregnant mothers is a major factor in determining the extent of utilization of antenatal service (WHO et.at., 2007; Carroli et al., 2001). levels of education and knowledge were the most important predictors of ANC utilization (Yang et al., 2010).

Generally, In Ethiopia, access to health care services is improving, the country has faced challenges in increasing health care utilization and the proportion of women who give birth with the assistance of skilled attendants is the lowest in Sub-Saharan Africa (Gurmesa 2009). The objective of this study is to know the percentage of women who know the about the service of Antenatal care utilization in Addis Ababa, Ethiopia.

\section{METHODS AND MATERIALS}

\section{Study design}

Institution based cross-sectional study was conducted to assess the knowledge of pregnant women on the benefit of ANC utilization in Addis Ababa.

Study area and period

The study was conducted in Addis Ababa, the capital city of Ethiopia with total population of more than three million. The city has six hospitals and 84 health centers under Addis Ababa regional health bureau, five specialized referral hospitals, two defense forces referral hospital and one Federal police hospital for public service. The study was carried out among women attending ANC in selected health center from January to May 2015.

\section{Population Source population}

All pregnant women who visited health centers that are found in Addis Ababa for the purpose of antinatal care service from March to April, 2015

Study population

Systematically selected Pregnant women attending ANC in randomly selected health centers from March to April, 2015.

\section{Inclusion and exclusion criteria}

Inclusion criteria

Pregnant women who had at least one previous ANC visit during their current pregnancy and those who were willing to participate were included in the study.

\section{Exclusion criteria}

Pregnant women that were ill to participate in an interview and first visit were excluded from the study.

\section{Sample size determination}

Sample size is calculated using single population proportion: $\mathrm{n}=$ sample size, $\mathrm{P}=$ prevalence of sexual abuse $=50 \%$ $\mathrm{d}$ margin of error $5 \%, Z \alpha / 2=$ critical value at $95 \%$ confidence level of certainty $(1.96) n=(Z \alpha / 2)^{2} p(1-p) / d 2$.

Hence proportion of women who had good knowledge toward utilization of ANC among women attending ANC clinic were not found, $50 \%$ proportion is considered to get maximum sample size. Therefore, with $10 \%$ nonresponse rate the final sample size was found to be $\underline{\underline{422}}$.

\section{Sampling procedure}

From the total of 84 health centers that are found in Addis Ababa 25 health centers were randomly selected and number of women to be included in these health centers were determined by using proportion to size allocation technique. The total number of women to be included in each health center were determined based the average number women expected to be seen during the data collection period based on the previous three-month data from the respected health center. Interval sampling was used to select women to be included in the study. To identify the interval, the average number of women expected per day in each health center was divided by number of women to be interviewed per day from respective health center. The first woman was selected by lottery method and then every $\mathrm{k}^{\text {th }}$ woman (which was calculated for each health center) visiting the health center was selected for the study. The immediately next woman was used if the woman is interviewed previously or she refused to participate in the study.

\section{Operational definitions}

Knowledgeable: 20 questions were asked for the knowledge part, each correct answer was given one mark and no mark were given for wrong answer and women with mean score for knowledge questions of 0.5 is considered to be knowledgeable.

Good knowledge: Those participant who scored above or equal to the mean score was considered to have good knowledge. Among 20 questions on knowledge, those who scored 13.01 and above was considered in this category. Poor knowledge: Those participant who scored below the mean score was considered to have good knowledge. Among 20 questions on knowledge, those who scored below 13.01 was considered in this category. 


\section{Data collection instrument}

Interviewer administered structured questionnaire was used with modification from other researches as presented in literature review. The questionnaire was prepared originally in English and then translated to Amharic language and then back to English. Five percent of the questionnaires were pretested for clarity and consistency of the questions in none selected health center week prior to the actual data collection. Then necessary correction was made based on the feedback of the data collectors.

\section{Data Collectors}

A total of 25 nurses one for each health center who are not working in maternal and child health service area were interview the women. One days training was given for data collectors and three supervisor on the objective and relevance of the study, how to gather the appropriate information, procedures of data collection techniques and the whole contents of the questionnaire. The supervisor monitored the overall data collection presses during the data collection period.

\section{Data processing \& analysis}

Epi data version 3.5 and SPSS version 21 was used for data entry and analysis. After cleaning the data, frequencies and percentages was calculated to all variables which were related to the objectives of the study. Odds ratio with $95 \%$ confidence interval was computed to assess the presence and degree of association between dependent and independent variables. P-value less than 0.05 was considered significant. Moreover, logistic regression analysis was also be employed to control the possible confounding effect and assess the separate effects of the variables.

\section{Ethical consideration}

Ethical clearance was obtained from Addis Ababa University, college of health science, department of nursing and midwifery ethical review committee. Permission was obtained from Addis Ababa health bureau and from respective health institutions, and informed consent was obtained from individual respondent. Questionnaire were analyzed, and the respondents were told that they have the right to be involved or not to be involved in the study, and that noninvolvement otherwise will not affect the clinical care they might receive.

\section{RESULT}

\section{Demographic Characteristics}

Out of 422 calculated sample size calculated a total of 405 women agreed to participate in this study making response rate $95.9 \%$. The mean age for the study subject was $27.63( \pm 5.07)$ majority $268(66.2 \%)$ of them being greater than 25 years of age. The majority $316(78.0 \%)$ were currently living with their partners and $215(53.1 \%)$ had educational status of greater than $9^{\text {th }}$ grade. The largest number of the respondents $138(34.1 \%)$ were housewife's followed by government employee 99(24.4\%). Two hundred twenty-four $(55.3 \%)$ of the women were followers of orthodox Christianity. Regarding their ethnic group 173(42.7\%) of them were from Amhara followed by Oromo which accounts for $103(25.4 \%)$ of the study participants. Two hundred eighty-four $(70.1 \%)$ of the women had reported as they have seen, heard or read about ANC in the past three months. And 284(70.1\%) of the women has said that they get any support they need related to ANC from their partner. (Table 1).

Table 1 Socio-demographic characteristics of women attending ANC services in selected health center, Addis Ababa, Ethiopia, $2015(\mathrm{~N}=405)$ 


\begin{tabular}{|l|l|l|}
\hline Characteristics & Frequency & Percentage \\
\hline Age & & \\
\hline $15-24$ & 137 & 33.8 \\
\hline $25+$ & 268 & 66.2 \\
\hline Current marital status & & \\
\hline Currently living with partner & 316 & 78.0 \\
\hline Currently not living with partner & 89 & 22.0 \\
\hline Educational status & & \\
\hline Less than grade 8 & 190 & 46.9 \\
\hline Grade 9 and above & 215 & 53.1 \\
\hline Occupation & 75 & 24.1 \\
\hline House wife & 138 & 34.1 \\
\hline Government employee & 99 & 24.4 \\
\hline Privet employee & 91 & 22.5 \\
\hline Merchant & 57 & 14.1 \\
\hline Others & 20 & 4.9 \\
\hline Religion & & \\
\hline Orthodox & 224 & 55.3 \\
\hline Muslim & 111 & 27.4 \\
\hline Protestant & 67 & 16.5 \\
\hline Others & 3 & 7 \\
\hline Ethnicity & & \\
\hline Amhara & 173 & 42.7 \\
\hline Oromo & 103 & 25.4 \\
\hline Tigre & 56 & 13.8 \\
\hline Gurage & 57 & 14.1 \\
\hline Others & 15 & 3.2 \\
\hline In the past three months, have you seen, heard or read anything & 70.1 \\
\hline Yes & 284 & 29.9 \\
\hline No & & \\
\hline Partner support & & \\
\hline Yes & & \\
\hline No & & \\
\hline
\end{tabular}

\section{Reproductive history}

Regarding history of previous pregnancies, from 405 women who responded to the questionnaire 210(51.9) of them reported as they have been pregnant before. The number of the respondent's children ranged between one and seven per women with $16.2 \%$ of them having more than three children. A total of 186 women $(88.6 \%)$ had visited health facilities for ANC services during their most recent pregnancy. Related to place of the most recent delivery $103(51.2 \%)$ of them delivered at health center and $11(5.5 \%)$ of them delivery at home with the main reason for this being precipitated labor (Table 2).

Table 2 Reproductive history of women attending ANC services in selected health center, Addis Ababa, Ethiopia, $2015(\mathrm{~N}=405)$ 


\begin{tabular}{|c|c|c|}
\hline Characteristics & Frequency & Percentage \\
\hline \multicolumn{3}{|c|}{ Previous pregnancy $(\mathrm{N}=405)$} \\
\hline Yes & 210 & 51.9 \\
\hline No & 195 & 48.1 \\
\hline \multicolumn{3}{|c|}{ Number of pregnancy $(\mathrm{N}=210)$} \\
\hline$\leq 2$ & 113 & 53.8 \\
\hline$\geq 3$ & 97 & 46.2 \\
\hline \multicolumn{3}{|c|}{ Number of children $(\mathrm{N}=210)$} \\
\hline$\leq 2$ & 176 & 83.8 \\
\hline$\geq 3$ & 34 & 16.2 \\
\hline \multicolumn{3}{|c|}{ Years between delivery $(\mathrm{N}=203)$} \\
\hline$\leq 2$ years & 110 & 54.2 \\
\hline$\geq 2$ years & 93 & 45.8 \\
\hline \multicolumn{3}{|c|}{ Health facility for ANC during your most resent $(n=210)$} \\
\hline Yes & 186 & 88.6 \\
\hline No & 24 & 11.4 \\
\hline \multicolumn{3}{|c|}{ Place of most recent delivery $(\mathrm{n}=201)$} \\
\hline \begin{tabular}{|l|} 
Home \\
\end{tabular} & 11 & 5.5 \\
\hline Health center & 103 & 51.2 \\
\hline Hospital & 51 & 25.4 \\
\hline Private hospital & 36 & 17.9 \\
\hline
\end{tabular}

\section{Knowledge on antenatal care}

In this study, the knowledge score of the respondents ranged between 7 and 18 with the mean of $13.01(\mathrm{SD}=3.976)$ and median of 13.0 (Interquartile Range, IQR=5). The score was normally distributed. The proportion of respondents with good knowledge was 59.3 percent with $95 \%$ confidence interval of 54.3 to 64.0 percent (figure $1)$.

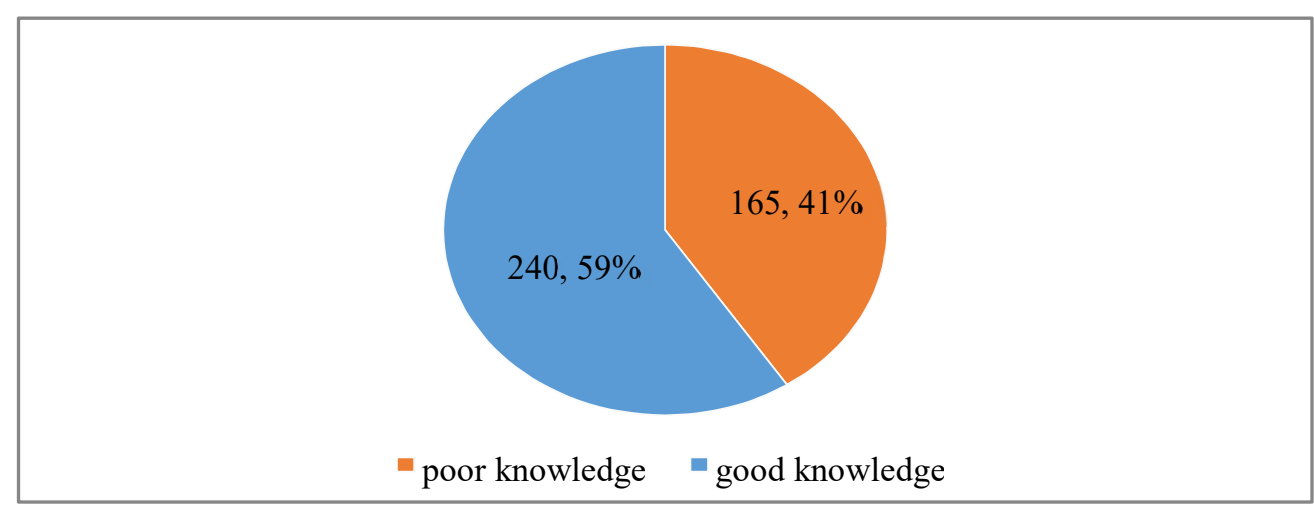

Figure 1 Knowledge on antenatal care among women attending ANC services in selected health center, Addis Ababa, Ethiopia, 2015.

Further analysis of the items on knowledge revealed that majority $(96.8 \%)$ of the women know that pregnant women need to go for antenatal check-up. However, only $40.2 \%$ know that the first antenatal check-up should be done in the first three months and about a quarter of the women know how many times does pregnant woman need to come for antenatal follow up throughout her pregnancy (table 3). 
Table 3 Knowledge on antenatal care among women attending ANC services in selected health center, Addis Ababa, Ethiopia, $2015(\mathrm{~N}=405)$

\begin{tabular}{|c|c|c|}
\hline Knowledge on antenatal care & Correct answer & Percentage (\%) \\
\hline Do pregnant women need to go for antenatal check-up? & 392 & 96.8 \\
\hline $\begin{array}{l}\text { If yes is it required to go for ANC even if there is no complication } \\
\text { during pregnancy? }\end{array}$ & 305 & 75.3 \\
\hline Should first antenatal check-up bed one in the first 3 months? & 163 & 40.2 \\
\hline $\begin{array}{l}\text { For at least how many times does pregnant woman need to come for } \\
\text { antenatal follow up throughout her pregnancy? }\end{array}$ & 105 & 25.9 \\
\hline Is it necessary to give inj. TT during pregnancy? & 294 & 72.6 \\
\hline If yes, how many times inj. TT should be given? & 117 & 28.9 \\
\hline Does pregnant woman need vitamin supplement? & 295 & 72.8 \\
\hline Is it necessary to take iron folic acid tablet during pregnancy? & 281 & 69.4 \\
\hline If yes, how many ion folic acid has to be taken during pregnancy? & 226 & 55.8 \\
\hline $\begin{array}{l}\text { Does pregnant woman need to take extra food as compared to } \\
\text { nonpregnant state? }\end{array}$ & 322 & 79.5 \\
\hline \multicolumn{3}{|c|}{$\begin{array}{l}\text { Does pregnant woman need to undergo the following test during her antenatal check- } \\
\text { up? }\end{array}$} \\
\hline Blood screening for HIV infection & 377 & 93.1 \\
\hline Blood screening for hemoglobin level & 202 & 49.9 \\
\hline Blood pressure examination? & 324 & 80.0 \\
\hline Blood sugar level? & 140 & 34.6 \\
\hline Can high blood pressure affect the fetus growth? & 303 & 74.8 \\
\hline Do diabetic women have higher risk of having big babies? & 164 & 40.5 \\
\hline Is ultrasound scan safe for the fetus? & 194 & 47.9 \\
\hline Is antenatal class good to prepare expecting mothers mentally? & 361 & 89.1 \\
\hline Can emotional disturbance affect fetal growth? & 214 & 52.8 \\
\hline Where is the ideal place a pregnant woman should deliver her baby? & 362 & 89.4 \\
\hline
\end{tabular}

\section{Determinants of with knowledge}

Predictor of knowledge of the women about ANC services as identified by using variables like, partner support was found to be significantly associated in binary regression. Women with partner support were 6.78 times more likely to have good knowledge compared to those who had no support from their partner [AOR 6.78(3.44,13.33)]. And other variables are not found to be significantly associated (Table 4). 
Table 4 Factors associated with knowledge of women attending ANC services in selected health center, Addis Ababa, Ethiopia, 2015.

\begin{tabular}{|c|c|c|c|c|}
\hline Characteristics & \multicolumn{2}{|c|}{ Knowledge of Women } & $\mathrm{COR}$ & \multirow[t]{2}{*}{$\mathrm{AOR}$} \\
\hline Age group & Good & Poor & & \\
\hline $15-24$ & $83(59.9)$ & $55(40.1)$ & $1.04(0.68,1.58)$ & $1.89(0.69,5.16)$ \\
\hline $25+$ & $158(59.0)$ & $110(41.0)$ & 1.00 & 1.00 \\
\hline \multicolumn{5}{|l|}{ Educational status } \\
\hline Less than grade 8 & $108(56.8)$ & $82(43.2)$ & $0.83(0.56,1.23)$ & $0.43(0.23,0.76)^{*}$ \\
\hline Grade 9 and above & $132(61.4)$ & $83(38.6)$ & 1.00 & 1.00 \\
\hline \multicolumn{5}{|l|}{ Number of children } \\
\hline$\leq 2$ & $107(60.8)$ & $69(39.2)$ & $1.75(0.83,3.65)$ & $1.61(0.58,4.49)$ \\
\hline$\geq 3$ & $16(47.1)$ & $18(52.9)$ & 1.00 & 1.00 \\
\hline \multicolumn{5}{|l|}{ Occupational status } \\
\hline House wife & $80(58.0)$ & $58(42.0)$ & $0.92(0.61,1.40)$ & $0.83(0.41,1.69)$ \\
\hline Others & $160(59.9)$ & $107(40.1)$ & 1.00 & 1.00 \\
\hline \multicolumn{5}{|l|}{ Partner support } \\
\hline Yes & $138(76.7)$ & $42(23.3)$ & $3.96(2.57,6.11)^{*}$ & $6.78(3.44,13.3)^{*}$ \\
\hline No & $102(45.3)$ & $123(54.7)$ & 1.00 & 1.00 \\
\hline \multicolumn{5}{|c|}{$\begin{array}{l}\text { In the past three months, have } \\
\text { you seen, heard or read } \\
\text { anything }\end{array}$} \\
\hline Yes & $167(58.8)$ & $117(41.2)$ & $0.94(0 . .61,1.45)$ & $0.52(0.24,1.11)$ \\
\hline No & $73(60.3)$ & $48(39.7)$ & 1.00 & 1.00 \\
\hline \multicolumn{5}{|c|}{ History of health care utilization for recent pregnancy } \\
\hline Yes & $112(60$ & 74( & $1.79(0.76,4$ & $2.69(2.58,4.37)^{*}$ \\
\hline No & $11(45$. & 13( & 1.00 & 1.00 \\
\hline
\end{tabular}

* Significant at $\mathrm{p}<0.05$

\section{DISCUSSION}

This study revealed that $59.3 \%$ of the respondents have good knowledge regarding the antenatal care. This finding is almost similar with cross-sectional study conducted in Metekel zone, North West Ethiopia, in which $65.6 \%$ of women interviewed knew at least half of the knowledge questions on ANC and so labeled as knowledgeable (Regassa 2011). Similarly, prevalence of good knowledge was lower $44.2 \%$ in Jempol, Negeria Semilan (Amosu et al., 2011). In another our hand finding was lower than study done in South-West Nigeria in which over all knowledge was reported to be $74.6 \%$. This deference may be due to difference in study population and instruments used to measure knowledge.

It is believed that women's education is important for understanding health messages and to be able to make decisions regarding their health and care. The findings on determinant factors shown that, although significant association found between educational status and knowledge of the women. As education level decrease the probability of having good knowledge also decreases. This finding is in line with study conducted in Metekel zone which showed educated are three times more likely to have knowledge of ANC (Gurmesa 2009). Education not only transforms, but also empowers women and improves their self-esteem. It is expected that educated women are more likely to be aware about their health status and seek health knowledge and this will contribute on utilization of ANC.

Partner support during pregnancy and ANC visit was found to be significant determinant of knowledge. Women with partner support had better knowledge. Previous exposure and utilization of ANC services may help in clearing myths about the service and help to appreciate the advantage of using the services. Likewise, the mother with previous health care service showed significant association with knowledge determining utilization of ANC.

\section{CONCLUSION AND RECOMMENDATION}

Three out of five women were found to have good Knowledge of ANC and Partner support was found to a significantly affect Knowledge. Women who has partner support had higher likely hood of having good knowledge. Compared to women with educational status greater than secondary school those with less than elementary school were less likely to have knowledge of ANC. In a long run, women empowerment through education and income 
generating activities as well as involvement of husbands during information education and communication are recommended

Limitation of the study

The study was the first in its type that it lacks adequate similar studies in our country for more comparative discussion.

\section{List of abbreviations}

AAU; Addis Ababa University, ANC; Antenatal care, EDHS; Ethiopian Demographic and Health Survey, GHC; Governmental health center, HC; Health center, HIV; Human immune deficiency virus, MOH; Ministry of Health, STI; Sexual transmitted infection, SPSS; Statistical Package for Social Science, UNICEF, United Nations International Children's Fund, WHO, World Health Organization.

\section{Declarations}

\section{Ethics approval and consent to participant}

Ethical approval was obtained from Institutional Review Board of Addis Ababa University, School of Allied Health Sciences, Department of Nursing and Midwifery and submitted to each health center. In addition, Permission was obtained to conduct the research from those Addis Ababa city administration health bureau. All participant that were involved in the study were asked for their willingness after they became informed about the purpose of the study and confidentiality of all the data. And an Informed written consent was obtained from all participants that were selected for the study. The study participants right to withdraw from the study at any time during data collection was respected.

\section{Consent for publication}

Not applicable.

\section{Availability of data and materials}

The data that support the findings of this study are available from the corresponding authors upon reasonable request.

\section{Competing interests}

The authors declare that they have no competing interests. All authors have read and approved the final manuscript. Funding

Addis Ababa University had covered all the costs for data collection instruments, data collection, data entry and Payments for supervisors and Advisors.

\section{Acknowledgements}

The authors would like to thank Addis Ababa University for funding this study and all study participants, supervisors and data collectors for their unreserved efforts and willingness to take part in this study.

\section{List of tables}

Table 1 Socio-demographic characteristics of women attending ANC services in selected health center, Addis Ababa, Ethiopia, $2015(\mathrm{~N}=405)$

Table 2 Reproductive history of women attending ANC services in selected health center, Addis Ababa, Ethiopia, $2015(\mathrm{~N}=405)$

Table 3 Knowledge on antenatal care among women attending ANC services in selected health center, Addis Ababa, Ethiopia, $2015(\mathrm{~N}=405)$

Table 4 Factors associated with knowledge of women attending ANC services in selected health center, Addis Ababa, Ethiopia, 2015

\section{List of figure}

Figure 1 Knowledge on antenatal care among women attending ANC services in selected health center, Addis Ababa, Ethiopia, 2015

\section{REFERENCE}

Adewoye KR1, Musa IO2, Atoyebi OA 1, Babatunde OA1. Knowledge and Utilization of Antenatal Care Services by Women of Child Bearing Age in Ilorin-East Local Government

Amosu, A. M., Degun, A. M., Thomas, A. M., Olanrewaju, F. M., Babalola, A. O., Omeonu, P. E., Ola, O. O. Onyeriude, O. O. \&Nwogwugwu, S. Acceptance and practice of focused antenatal care by health care providers in south west zone of Nigeria. Arch. Appl. Science Research, 3(10), 484-491. (2011).

Area, North Central Nigeria. International Journal of Science and Technology. Volume 3 No.3, March 2013

Carroli G, Rooney C, Villar J. How effective is antenatal care in preventing maternal mortality and serious morbidity? An overview of the evidence. Paediatric and Perinatal Epidemiology 2001;15 (supplement 1):142.

Effendi R, Isaranurug S, Chompikul J. Factors related to the utilization of antenatal care services among 
postpartum mothers in PasarRebo General Hospital, Jakarta, Indonesia. J Public Health Dev, 2008; 6: 113122

Gurmesa Tura. Antenatal Care Service Utilization and Associated Factors in Metekel Zone, Northwest Ethiopia. Ethiop J Health Sci. Vol.19, No. 2 July 2009.

Kalayou K Berhe, Haftom G Welearegay, Gerezgiher B Abera, Hailemariam B Kahsay and Alemayehu B Kahsay. Assessment of Antenatal Care Utilization and its Associated Factors Among 15 to 49 Years of Age Women in AyderKebelle, Mekelle City 2012/2013; A Cross sectional study. American Journal of Advanced Drug Delivery. 062-075, 2014

Ojo. A textbook for midwives in the Tropics (5th ed), London: Holden and Stoughton. 2004

Orc M et al; Ethiopia demographic and Health survey Addis Abeba Ethiopia and USA: CSA, 20111

Regassa N. Antenatal and postnatal care service utilization in southern Ethiopia a population based study. African Health Sciences. 1 1(3): 390 - 397(2011)

Rosalia, A. M. \& Muhammad, J. J. Knowledge, attitude and practices on antenatal care among orangasli women in Repel, Nigeria Sembelian. Malaysian. Journal of public health medicine, 11(2), 13-21(2011).

WHO, UNICEF. Revised 1990 Estimates of Maternal Mortality: A New Approach by WHO and UNICEF. Geneva: WHO and UNICEF. In Shiffman J and Okonofua F. E.The State of Political Priority for Safe Motherhood in Nigeria.BJOG.114: 127- 133. 2007

WHO; research progress report; WHO/FHE/MSM/94;18,1987-1992 program

Xiengkhouang Province, LAO PDR. Nagoya J. Med. Sci. 72. 23 33, 2010

Yang Ye, Yoshitoku Yoshida, Md. Harun-Or-Rashid And Junichi Sakamoto. Factors Affecting the Utilization of Antenatal Care Services Among Women In Kham District, 